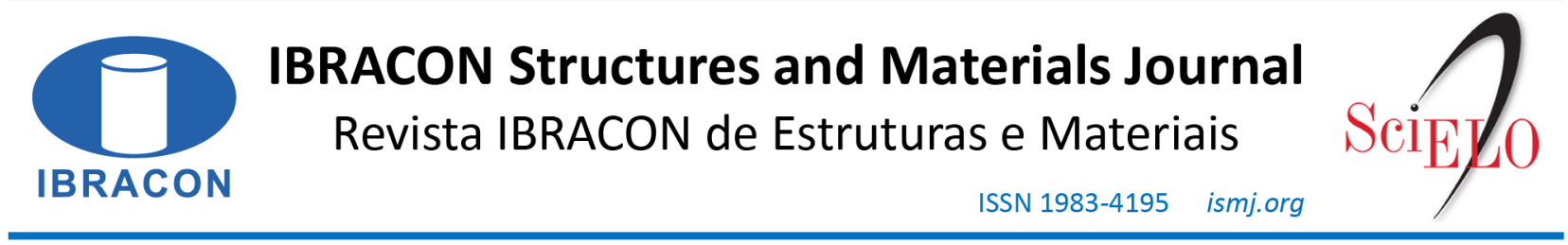

ORIGINAL ARTICLE

\title{
Parametric study of the strength of reinforced concrete polygonal sections submitted to oblique composite flexion
}

\section{Estudo paramétrico da resistência de seções poligonais de concreto armado submetidas à flexão composta oblíqua}

Lucas Peres de Souza ${ }^{a}$ (1)

Marco André Argenta ${ }^{\mathrm{a}}$

${ }^{a}$ Universidade Federal do Paraná - UFPR, Programa de Pós-graduação em Engenharia da Construção Civil - PPGECC, Curitiba, PR, Brasil

Received 21 March 2019

Accepted 28 February 2020

\begin{abstract}
This work aims to verify the influence of characteristic compressive cylinder strength $\left(f_{c k}\right)$, section geometry and eccentric axial load on the strength of square, cross, "T" and "L" reinforced concrete sections, under oblique composite flexion. A computational algorithm was created to calculate sections interaction diagram of bending strength, taking into account NBR 6118 idealized parabola-rectangle stressstrain relationships for 20 to $90 \mathrm{MPa} f_{c k}$ concretes. The results show that $f_{c k}$ influence is stronger for higher values of axial load and that the failure surface shape in interaction diagrams depends directly on the $f_{c k}$ and on the rebars distribution in the section. Furthermore, under lower compressive axial loads, higher oblique composite flexion strengths are reached when there is more reinforcement area in tension regions but, as the compression increases, the reinforcement presence and larger concrete areas in compression zones provide higher bending moment strengths.
\end{abstract}

Keywords: reinforced concrete, polygonal sections, oblique composite flexion.

Resumo: Este trabalho objetiva verificar a influência da variação da resistência do concreto $\left(f_{c k}\right)$, da geometria da seção transversal e do esforço axial de compressão excêntrico na resistência à flexão composta oblíqua de seções com formato quadrado, "cruz", "T" e "L", com mesmas áreas de concreto e de armaduras. Para isso, cria-se um algoritmo computacional que calcula as envoltórias de resistência, aplicando os diagramas tensão-deformação propostos pela NBR 6118:2014 para concretos com $f_{c k}$ de 20 a $90 \mathrm{MPa}$. Os resultados revelam que o $f_{c k}$ exerce maior influência para esforços de compressão mais elevados e que o $f_{c k}$ e a distribuição das barras de aço interferem diretamente no formato das envoltórias. Mostra-se também que, sob compressões baixas, a concentração das barras de aço nas zonas de tração leva às maiores resistências mas, à medida que a compressão cresce, a presença da armadura e de maiores áreas de concreto nas zonas de maior compressão é que induzem momentos resistentes maiores.

Palavras-chave: concreto armado, seções poligonais, flexão composta oblíqua.

How to cite: L. P. Souza and M. A. Argenta, "Parametric study of the strength of reinforced concrete polygonal sections submitted to oblique composite flexion," Rev. IBRACON Estrut. Mater., vol. 13, no. 5, e13512, 2020, https://doi.org/10.1590/S1983-41952020000500012

\section{INTRODUCTION}

Sections subjected to combined bending and axial load are recurrent in reinforced concrete structures. Generally, situations such as columns located in building corners, or even supporting two-way slabs, lead to such types of internal forces [1]. Usually, the representation of reinforced concrete sections strength of combined biaxial bending and axial load is made by axial force $(N)$ - bending moment $\left(M_{x}\right.$ and $\left.M_{y}\right)$ interaction diagrams. These diagrams calculation 
involves an internal section equilibrium iterative process, due to the physical nonlinearity problem because steel and concrete constitutive relationships. There are, in the literature, a variety of methods proposed to reach such strengths. Dall'Asta and Dezi [2] for example, develop an iterative method in which the main unknown of the problem is a minimum required reinforcement steel area, given a section geometry (arbitrary polygon), the number and location of the rebars, and the mechanical behavior materials. Fafitis [3] generates an algorithm based on the Green's theorem analytical integration of concrete compressive stresses, transforming the double integral integrals into integral line along the compressed polygons. Vaz Rodrigues [4], in turn, implements an algorithm based on the section subdivision into trapezoidal elements and uses the Gauss-Legendre stress integration over these elements.

In addition to the ways to reach the sections strengths, there is a need to evaluate the material properties (reinforced concrete) and section geometry effects on the results of these calculation algorithms. In 2014, NBR 6118 [5] began to contemplate concrete characteristic compressive cylinder strength $\left(f_{c k}\right)$ from 50 to $90 \mathrm{MPa}$ and proposed a parabolarectangle constitutive relationships to these materials. The equations proposed in this standard idealize the concrete stress-strain behavior as a parabola-rectangle curve and establish the possible deformation domains for reinforced concrete sections under combined bending and axial load by strains $\varepsilon_{c 2}$ (concrete compressive strain at the end of parabolic region) and $\varepsilon_{c u}$ (concrete ultimate compressive strain), calculated according to $f_{c k}$, combined with steel yield and ultimate strains, according to Figure 1.

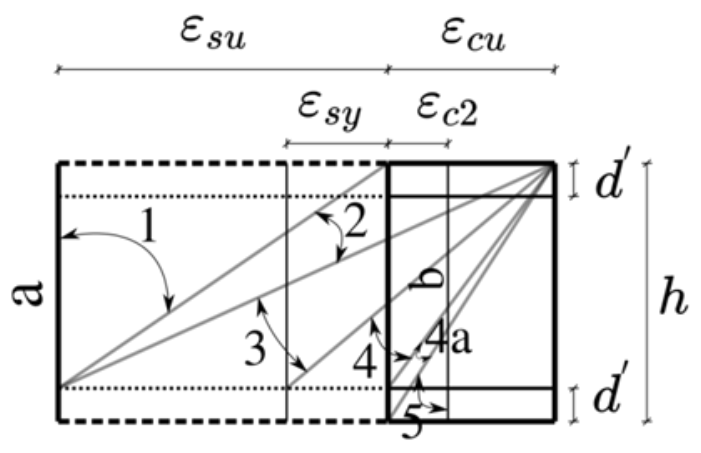

Figure 1. NBR 6118 [5] deformation domains for reinforced concrete sections under combined bending and axial load.

In this context, there are analytical and experimental works that help the understanding of the new formulations. Torrico [6], for example, studies the behavior of high strength concrete slender columns, analyzing, among other factors, the concrete ultimate limit states of rupture both experimentally and numerically.

With the investigation of section geometry effects there are also the possibility of optimizing reinforced concrete structural elements under combined bending and axial load, according to applied forces. Campione et al. [7] perform a study of the parameters such as concrete strength, section shape, confining level, reinforcement ratio and rebars distribution influence. The authors conclude, among other things, that increasing concrete strength does not modify the interaction diagram shape of the section with maximum curvature, although it provides an increase in section deformation capacity by reducing the dimensionless axial force $v$, calculated according to Equation 1 .

$v=\frac{N}{A_{c} f_{c d}}$

Based on what already exists in the literature and continuing the study of Souza [8], the present work objectives are: a) the verification of the influence of concrete $f_{c k}$ variation on the oblique composite flexion of square, cross-format, "T" and "L" reinforced concrete sections, applying the parabola-rectangle of NBR $6118 f_{c k}$ [5]; b) a comparison of the oblique composite flexion strength among different strength shapes with constant steel and concrete areas, considering the variation of concrete and axial force. 


\section{METHOD}

The analysis of the work is based on the results produced by a computational routine developed in Python 3 language, which reads the input data of the problem, generates the moment-axial force-curvature interaction diagrams and finally calculates the moment-axial force-curvature interaction diagrams for reinforced concrete sections, as shown in Figure 2.

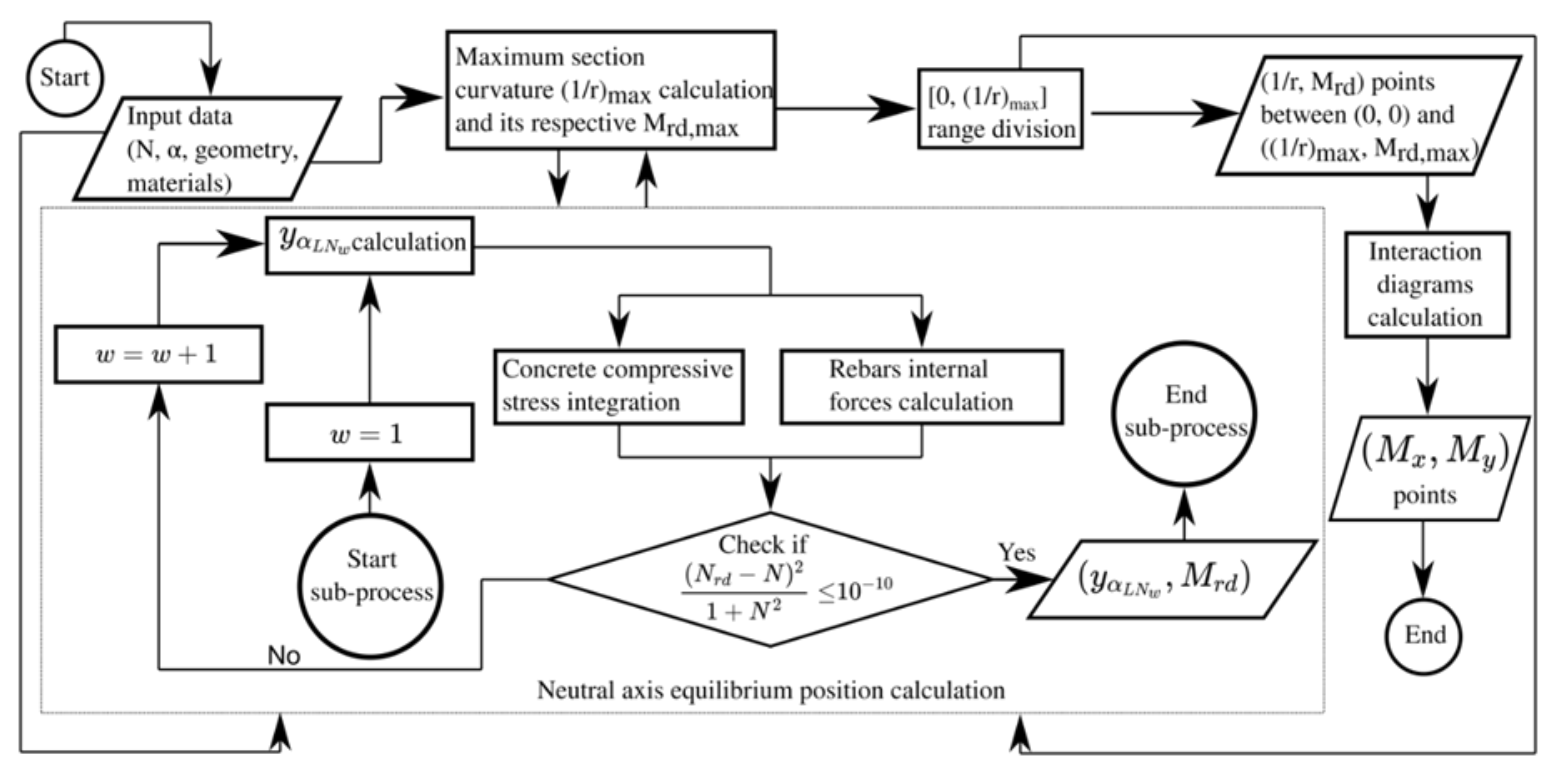

Figure 2. Method sequence.

\subsection{Input data}

The main input data of the problem are the sections geometry, materials constitutive relationships, neutral axis inclination angles and axial forces, for which the moment-axial force-curvature interaction diagrams were calculated.

In view of the definition of the problem geometry, we chose to analyze the square, cross-format, " $T$ " and " $L$ " sections of Figure 3 which have the same reinforcement area equal to $12.57 \mathrm{~cm}^{2}$ and concrete area equal to $625 \mathrm{~cm}^{2}$ (convenient values). The definition of $H_{x}, H_{y}, b_{x}$ e $b_{y}$ dimensions and of all sections departed from the square section of dimensions $25 \times 25 \mathrm{~cm}$. Thus, it was arbitrated that, in cross-format, "T" and "L" the section dimensions $H_{x}=H_{y}$ and $b_{x}=b_{y}=H_{x} / 3=H_{y} / 3$. With such dimension relations and with the concrete area remaining constant, it was possible to calculate the dimensions in Figure 3

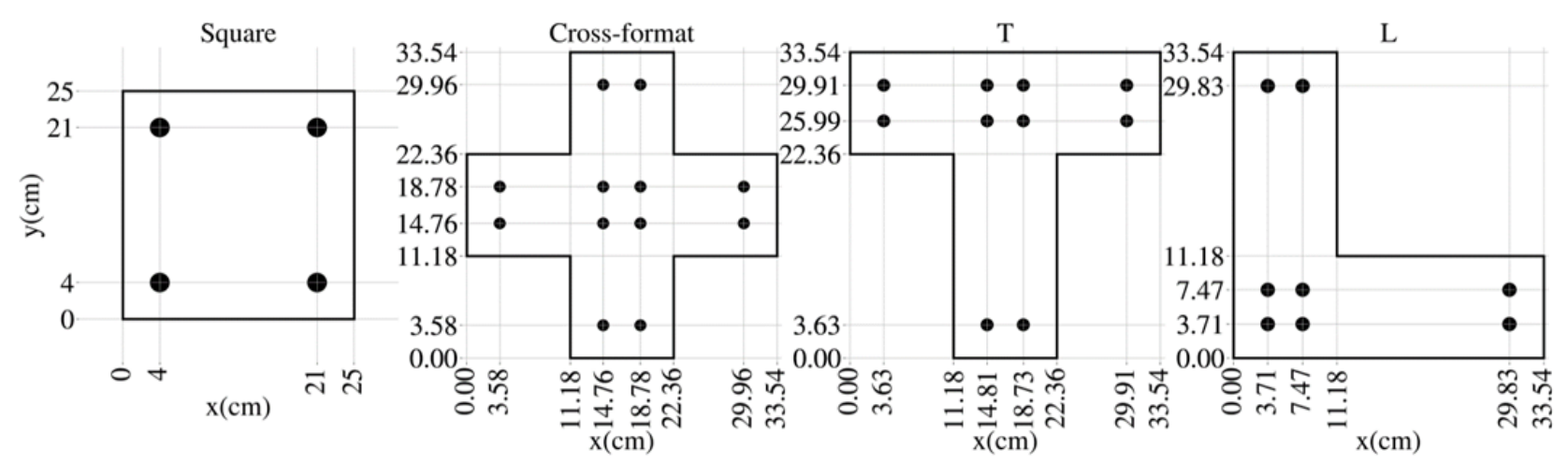

Figure 3. Geometry of analyzed sections. 
The definition of the rebars distribution and respective area followed a similar script, in which the first decision is the fixation of the square section reinforcement detailing, with 4 rebars of diameter $\phi_{l}$ equal to $2 \mathrm{~cm}$, symmetrically distributed, with $d^{\prime}$ distances between section edges and rebars centroid equal to the sum of the concrete nominal cover $c_{\text {nom }}$, equal to $2.5 \mathrm{~cm}$, with the transverse reinforcement diameter $\phi_{t}$, equal to $0.5 \mathrm{~cm}$, and with longitudinal rebars radius $(1 \mathrm{~cm})$, resulting in $d^{\prime}$ equal to $4 \mathrm{~cm}$.

By fixing the reinforcement area $A_{s}$ at $12.57 \mathrm{~cm}^{2}$ and using the same value to $c_{n o m}$ and $\phi_{t}$ from all sections, a longitudinal rebars area for the sections with other shapes is calculated, and the criterion to define the quantity of rebars was the minimum quantity required to enable transverse fixation reinforcement.

Concrete characteristic compressive cylinder strength $\left(f_{c k}\right)$ range from 20 to $90 \mathrm{MPa}$ by $10 \mathrm{MPa}$, i.e. the range of values encompassed by NBR 6118 [5].

The equations for the mathematical representation of the concrete and steel constitutive relationships are also defined from NBR [5]. Concrete tensile strength is neglected and its compressive behavior is represented by the idealized parabola-rectangle diagram, described by Equations 2 to 5 and generalized for application in concretes up to $90 \mathrm{MPa}$. In turn, the CA-50 longitudinal reinforcement steel has its behavior described by NBR 6118 [5] bilinear elastic perfectly plastic stress-strain relationship, represented by Equation 6, for both tensile and compressive strains.

$$
\begin{aligned}
& \sigma_{c}=\left\{\begin{array}{c}
0.85 f_{c d}\left[1-\left(1-\frac{\varepsilon_{c}}{\varepsilon_{c 2}}\right)^{n}\right], \text { if } 0 \leq \varepsilon_{c} \leq \varepsilon_{c 2} \\
0.85 f_{c d}, \text { if } \varepsilon_{c 2} \leq \varepsilon_{c} \leq \varepsilon_{c u}
\end{array}\right. \\
& \varepsilon_{c 2}=\left\{\begin{array}{c}
0.2 \%, \text { if } f_{c k} \leq 50 \mathrm{MPa} \\
0.2 \%+0.0085 \%\left(f_{c k}-50\right)^{0.53}, \text { if } 50<f_{c k} \leq 90 \mathrm{MPa}
\end{array}\right. \\
& \varepsilon_{c u}=\left\{\begin{array}{c}
0.35 \%, \text { if } f_{c k} \leq 50 \mathrm{MPa} \\
0.26 \%+3.5 \%\left(\frac{90-f_{c k}}{100}\right)^{4}, \text { if } 50<f_{c k} \leq 90 \mathrm{MPa}
\end{array}\right. \\
& n=\left\{\begin{array}{c}
2, \text { if } f_{c k} \leq 50 \mathrm{MPa} \\
1.4+23.4\left(\frac{90-f_{c k}}{100}\right)^{4}, \text { if } 50<f_{c k} \leq 90 \mathrm{MPa}
\end{array}\right. \\
& \sigma_{s}=\left\{\begin{array}{c}
\varepsilon_{s} E_{s}, \text { if } \varepsilon_{s} \leq \frac{f_{y d}}{E_{s}} \\
f_{y d}, \text { if } \frac{f_{y d}}{E_{s}}<\varepsilon_{s} \leq 1 \%
\end{array}\right.
\end{aligned}
$$

where $\sigma_{c}=$ concrete compressive stress; $f_{c d}=$ concrete compressive strength design value; $\varepsilon_{c}=$ concrete compressive strain; $\varepsilon_{c 2}=$ concrete compressive strain at the end of parabolic region; $n=$ parabolic region exponent; $\varepsilon_{c u}=$ concrete ultimate compressive strain; $f_{c k}=$ concrete characteristic compressive cylinder strength; $\sigma_{s}=$ rebar stress; $\varepsilon_{s}=$ rebar strain; $E_{s}=$ rebar steel elastic modulus design value; $f_{y d}=$ rebar steel design yield strength

Axial force values applied to sections, $N$, vary depending on the type of analysis desired. In the analysis of the influence of $f_{c k}$, values shift from 500 to $1200 \mathrm{kN}$ by $100 \mathrm{kN}$ for square and cross-format sections. For "T" sections, $N$ values shift from 500 to $1000 \mathrm{kN}$ by $100 \mathrm{kN}$ and, for "L" sections, from 500 to $1100 \mathrm{kN}$ by $100 \mathrm{kN}$. Different limit superior values $(1000,1100$ and $1200 \mathrm{kN})$ are used because maximum section axial strength is different for each section shape.

Flexural strength comparisons among different section shapes are done for sections subjected to the same dimensionless axial force $v$, considering that sections compared have the same concrete area and $f_{c k}$. 
Neutral axial inclination angle, $\alpha$, range from 0 to $2 \pi$ rad by $\frac{\pi}{360} \operatorname{rad}(720$ increments) for moment-axial forcecurvature interaction diagrams calculation.

\subsection{Moment-axial force-curvature interaction diagrams calculation}

Moment-axial force-curvature interaction diagrams determine the correspondence between the section curvature and the respective flexural strength, based on the axial force $N$, neutral axis inclination angle and section geometry.

Figure 4 iterative process, based on the bisection method, is used to find the section maximum allowed curvature before concrete crushing or reinforcement steel elongation limit. The interval containing the solution is repeatedly bisected until the relative variation between two consecutive iterations is less than $1 \%$.

Rupture verification, inside the section maximum allowed curvature calculation, is done by another iterative algorithm, that aims to calculate neutral axis equilibrium position $y_{\alpha_{L N}}$. This procedure is applied to find the section strain field that balances the section curvature $(1 / r)_{k}$ and the applied axial force $N$. As in the algorithm that achieves a section maximum allowed curvature, the bisection method is used until the relative variation between the section axial strength and the applied axial force is less than $1 \%$.

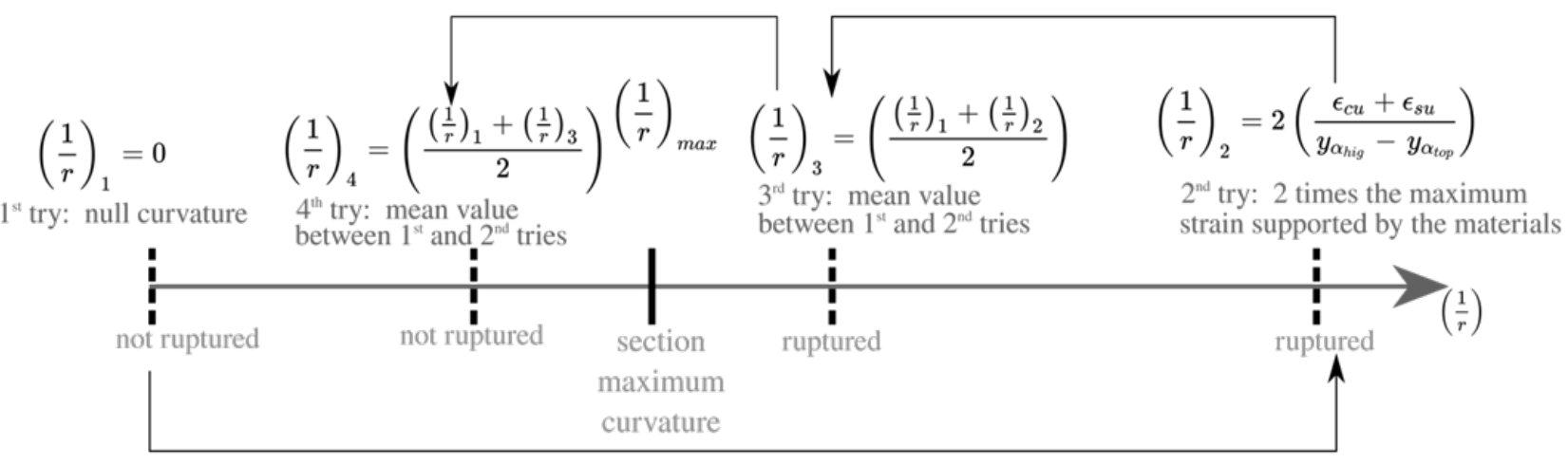

Figure 4. Illustrative scheme of bisection process used to find the section maximum allowed curvature.

Concrete compressive stress integration is solved by using numerical integration to determine the compressed area, the $y_{\alpha_{\varepsilon_{c}}}$ coordinate is calculated according to Equation 7.

$y_{\alpha_{\varepsilon_{c 2}}}=y_{\alpha_{L N_{w}}}+\varepsilon_{c 2} /(1 / r)_{k}$

where $y_{\alpha_{\varepsilon_{c}}}=y_{\alpha}$ coordinate that corresponds to $\varepsilon_{c 2}$ strain; $y_{\alpha_{L N_{w}}}=$ neutral axis $y_{\alpha}$ coordinate in iteration $w$; $(1 / r)_{k}=$ section curvature in iteration $k$.

The compressed areas vertex coordinates are determined according to Figure 5, using the Python's Shapely package (geometry.polygon.intersection), from the python shapely package, developed by Gillies [9]. The area polintersec results from the intersection between the infinite region $\mathrm{pol}_{2}$ above neutral axis and section region pol ${ }_{1}, \mathrm{using}\left(x_{\alpha}, y_{\alpha}\right)$ coordinates.

Then, pol ${ }_{\text {intersec }}$ area is meshed with triangles, using Python's MeshPy package (meshpy.triangle),developed by Klöckner [10]. Mesh generation is controlled by triangles maximum area set as $10 \mathrm{~cm}^{2}$. This value represents a balance between computational processing time and results expected precision. The mesh generation output data is a set of $n_{t}$ matrices $\left[\right.$ tri $_{t_{3 \times 2}}$ containing triangle elements vertex coordinates $\left(x_{\alpha}, y_{\alpha}\right)$ in compressed area, as in Equation 8 . 
$[t r i]_{t_{3 x 2}}=\left[\begin{array}{cc}x_{\alpha_{t, l}} & y_{\alpha_{t, l}} \\ x_{\alpha_{t, 2}} & y_{\alpha_{t, 2}} \\ x_{\alpha_{t, 3}} & y_{\alpha_{t, 3}}\end{array}\right]$

where $[t r i]_{t_{3 \times 2}}=$ vertex coordinates matrix of $t$-th triangle.

Concrete axial strength $R_{c d}$ and its respective position coordinates $x_{\alpha_{R_{c d}}}$ and $y_{\alpha_{R_{c d}}}$ are calculated according to compressive stress integration Equations 9 and 10 over pol intersec area $A_{p o l}$.

$R_{c d}=\int_{A_{p o l}} \sigma_{c} d A$

$y_{\alpha_{R_{c d}}}=\frac{\int_{A_{p o l}} y_{\alpha} \sigma_{c} d A}{R_{c d}}$ and $x_{\alpha_{R_{c d}}}=\frac{\int_{A_{p o l}} x_{\alpha} \sigma_{c} d A}{R_{c d}}$

where $R_{c d}=$ concrete axial strength; $A_{p o l}=$ pol $l_{\text {intersec }}$ area; $y_{\alpha_{R_{c d}}}=$ concrete axial strength position $y_{\alpha}$ coordinate; $x_{\alpha_{R_{c d}}}=$ concrete axial strength position $x_{\alpha}$ coordinate.

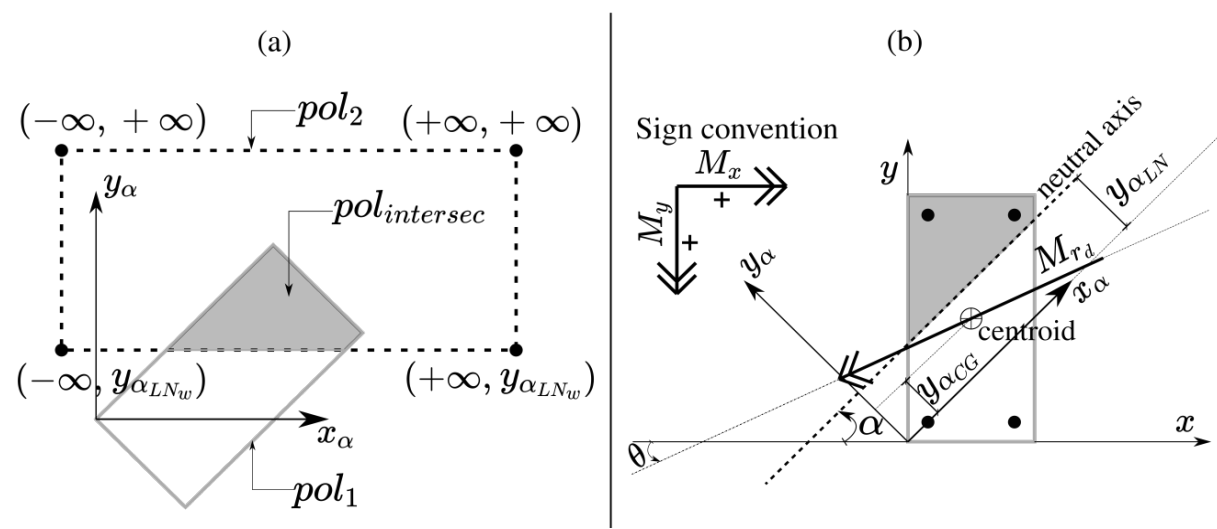

Figure 5. (a) Polygon intersection demonstration; (b) Difference between neutral axis angle $\alpha$ and flexural strength angle $\theta$.

Considering $A_{p o l}$ subdivision in $n_{t}$ triangles, Equations 9 and 10 integrals are rewritten as sums of integrals over triangles areas $A_{t r r_{i}}$ (Equations 11 and 12).

$\int_{A_{p o l}} \sigma_{c} d A=\sum_{t=1}^{n_{t}} \int_{A_{w_{t}}} \sigma_{c} d A$

$\int_{A_{p o l}} y_{\alpha} \sigma_{c} d A=\sum_{t=1}^{n_{t}} \int_{A_{v_{i}}} y_{\alpha} \sigma_{c} d A$ and $\int_{A_{p o l}} x_{\alpha} \sigma_{c} d A=\sum_{t=1}^{n_{t}} \int_{A_{\text {trit }}} x_{\alpha} \sigma_{c} d A$

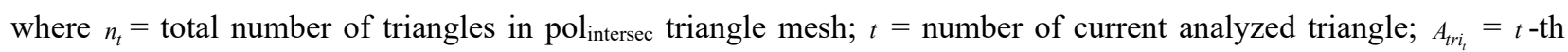
triangle area.

Then, Equations 11 and 12 are solved using Gauss-Legendre quadrature and concrete axial $R_{c d}$ and flexural strengths $M_{c d}$ are calculated by Equations 9 and 13 . 
$M_{c d}=\left[\left(y_{\alpha_{R_{c d}}}-y_{\alpha_{c g}}\right)^{2}+\left(x_{\alpha_{R_{c d}}}-x_{\alpha_{c g}}\right)^{2}\right]^{0.5} R_{c d}$

where $M_{c d}=$ concrete flexural strength; $y_{\alpha_{R_{c d}}}=$ section centroid $y_{\alpha}$ coordinate; $x_{\alpha_{R_{d d}}}=$ section centroid $x_{\alpha}$ coordinate.

In addition, axial strength rebars $R_{S_{b}}$ are calculated according to Equation 14 and depends on the stress in $\sigma_{s_{b}}$ each rebar, obtained by Equation 6 and using Equation 15 to determine rebars $\varepsilon_{s_{b}}$ strain.

$R_{s_{b}}=A_{s_{b}} \sigma_{s_{b}}$

$\varepsilon_{s_{b}}=\left(y_{\alpha_{b}}-y_{\alpha_{L N_{w}}}\right)$

where $R_{s_{b}}=$ rebar axial strength; $A_{s_{b}}=$ rebar area; $\sigma_{s_{b}}=$ rebar stress; $\varepsilon_{s_{b}}=$ rebar strain; $y_{\alpha_{b}}=$ rebar centroid $y_{\alpha}$ coordinate.

Next, Equation 16 is used to calculate rebars flexural strength $M_{s_{b}}$ :

$M_{s_{b}}=\left[\left(y_{\alpha_{b}}-y_{\alpha_{c g}}\right)^{2}+\left(x_{\alpha_{b}}-x_{\alpha_{c g}}\right)^{2}\right]^{0.5} R_{s_{b}}$

where $M_{s_{b}}=$ rebar flexural strength; $x_{\alpha_{b}}=$ rebar centroid $x_{\alpha}$ coordinate.

Thus, reinforcement axial $R_{s d}$ and flexural $M_{s d}$ strength is calculated by Equations 17 and 18, by summing over all rebars strengths.

$R_{s d}=\sum_{b=1}^{n_{\text {rebars }}} R_{S_{b}}$

$M_{s d}=\sum_{b=1}^{n_{\text {rebars }}} M_{s_{b}}$

where $R_{s d}=$ reinforcement axial strength; $n_{\text {rebars }}=$ number of rebars in the section; $M_{s d}=$ reinforcement flexural strength.

Therefore, section axial $N_{r d}$ and flexural $M_{r d}$ strength is established in Equations 19 and 20 by summing concrete and reinforcement contributions:

$N_{r d}=R_{c d}+R_{s d}$

$M_{r d}=M_{c d}+M_{s d}$

where $N_{r d}=$ section axial strength; $M_{r d}=$ section flexural strength.

In summary, $N_{r d}$ and $M_{r d}$ are the section strengths that balance the equilibrium for a section with a curvature $(1 / r)_{k}$ and a neutral axis inclination angle $\alpha$, subjected to an applied axial force $N$. 


\subsection{Bending moment-axial force interaction diagrams calculation}

Bending moment-axial force interaction diagrams curves are sets of points represented by combined loads (bending and axial) that lead to section failure. These points are determined based on moment-axial force-curvature data processing. Each $(N, \alpha)$ pair determine a maximum flexural strength $M_{r d}$, its respective $\theta$ inclination angle from the $x$ axis and its respective neutral axis equilibrium position, as illustrated in Figure 5b. Difference between $\alpha$ and $\theta$ angles is due to the asymmetric distribution of concrete compressive stresses and of the rebars stresses in relation to the neutral axis perpendicular line.

The interaction diagrams points coordinates are the applied axial force $N=N_{r d}$ and the maximum flexural strengths around $x, M_{x}=-M_{r d} \cos \theta$, and $y$ axis, $M_{y}=M_{r d} \sin \theta$.

\section{RESULTS}

\subsection{Concrete characteristic compressive cylinder strength $\left(f_{c k}\right)$ influence on section flexural strength}

Interaction diagrams of sections with same geometry and subjected to the same applied axial force $N$, but with different $f_{c k}$ values, are compared in order to analyze the $f_{c k}$ influence on sections flexural strength.

Figure 6 show comparisons for square, cross-format and " $\mathrm{T}$ " sections. $N$ values applied to the square sections are $N=500 \mathrm{kN}, N=800 \mathrm{kN}$ and $N=1200 \mathrm{kN}$. Regarding to the cross-format sections, $N$ values also vary from 500 to $1200 \mathrm{kN}$ and the results are presented for $N=500 \mathrm{kN}, N=800 \mathrm{kN}$ and $N=1200 \mathrm{kN}$. "T" sections, in turn, are subjected to applied axial load values that range from 500 to $1000 \mathrm{kN}$ and Figure 6 exhibits interaction diagrams comparison for $N=500 \mathrm{kN}, N=800 \mathrm{kN}$ and $N=1000 \mathrm{kN}$. Figure 7 present the results for "L" sections compressed by $N=500 \mathrm{kN}$ (minimum applied axial load), $N=800 \mathrm{kN}$ and $N=1100 \mathrm{kN}$ (maximum applied axial load), respectively. Table 1 summarizes the interaction diagrams results presented in Figures 6 and 7 , for $\theta$ angles varying from 0 to $\frac{7 \pi}{4}$ rad, shifted by $\frac{\pi}{4} \mathrm{rad}$, in order to facilitate the numeric reading of figures results.

The use of axial force absolute values instead of dimensionless axial force $v$ was chosen because $f_{c k}$ is variable and, consequently, for the same section subjected to a constant $v, N$ absolute value would also vary with the $f_{c k}$, something that could distort comparisons.

\subsection{Shape influence on section flexural strength}

Shape influence on section flexural strength is evaluated by comparing side by side the flexural strength interaction diagrams of square, cross-format, " $\mathrm{T}$ " and "L" sections of Figure 3, that are composed of concretes of the same $f_{c k}$, same reinforcement steel area and subjected to the same dimensionless axial force $v$. It is noteworthy that, in this case, the analysis by the rates of dimensionless axial force $v$ is possible because the graphs deal with the same $f_{c k}$ and the same concrete area.

Analyzed sections are composed of 20,50,60 and $90 \mathrm{MPa} f_{c k}$ concretes. These values are selected considering that 20 and $90 \mathrm{MPa}$ are the NBR 6118 [5] stress-strain relationship extreme values and 50 and $60 \mathrm{MPa}$ are values next to the point where Equation 2 change. Figure 8 show interaction for 20 and $50 \mathrm{MPa}$ concrete sections and Figure 9 present comparisons among section shape flexural strengths of 60 and $90 \mathrm{MPa}$ concrete sections.

\section{DISCUSSION}

\subsection{Concrete characteristic compressive cylinder strength $\left(f_{c k}\right)$ influence on section flexural strength}

The results show three important issues related to $f_{c k}$ effect on section flexural strength: a) the $f_{c k}$ variation produced little effect on flexural strength of sections under low axial forces magnitude. However, this effect is enhanced when applied axial force is increased; $b$ ) the shape of flexural strength interaction diagrams tends to be modified as the compression is increased, but sections with $f_{c k} \leq 50 \mathrm{MPa}$ and with $f_{c k}>50 \mathrm{MPa}$ present opposing trends; c) mainly low axial forces out of sections principal axis of inertia (oblique composite flexion), the $50 \mathrm{MPa}$ sections axial strength is greater than the 60 and $70 \mathrm{MPa}$ one. 

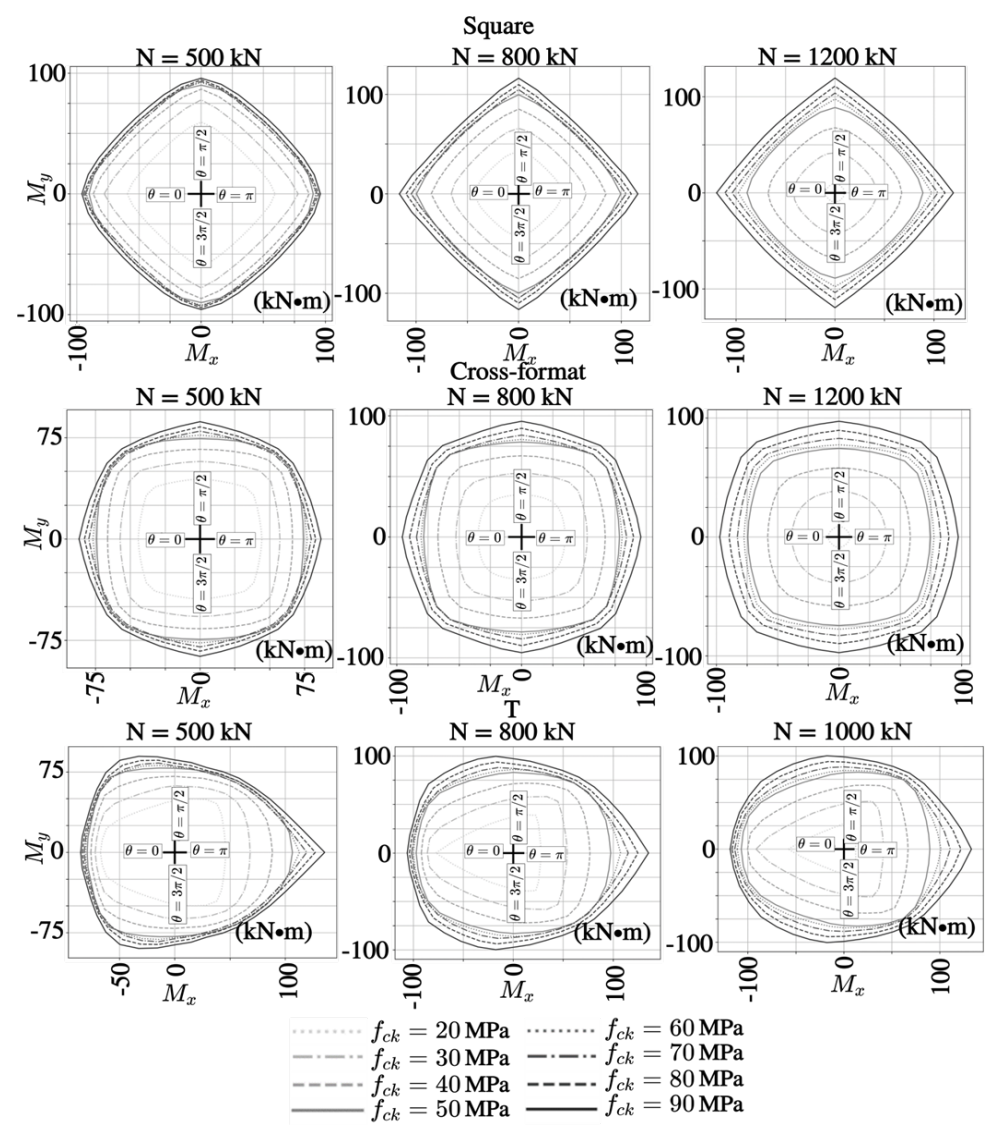

Figure 6. Influence of $f_{c k}$ on square, cross-format and " $T$ " sections flexural strength.

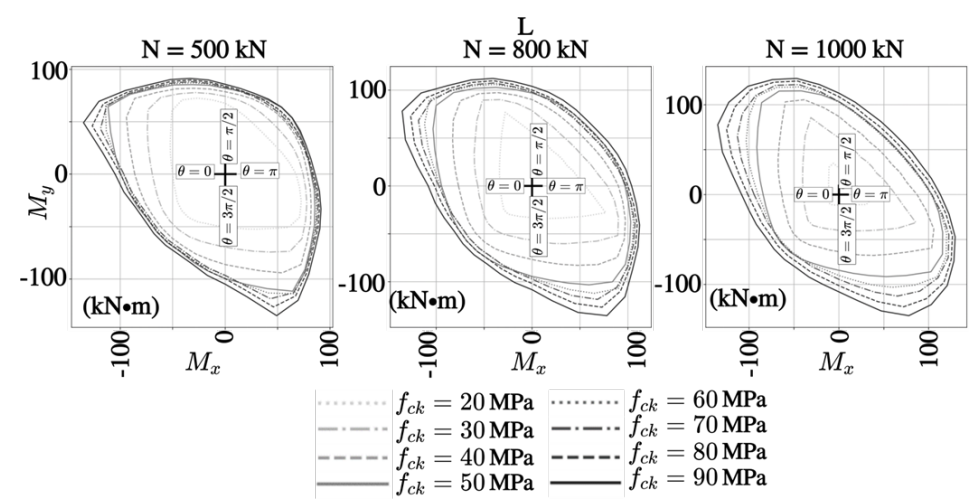

Figure 7. Influence of $f_{c k}$ on " $\mathrm{L}$ " sections flexural strength.

In square sections, flexural strength interaction diagrams of sections with 50,60,70 and $80 \mathrm{MPa} f_{c k}$ are remarkably close, to the point of almost matching under axial force of $500 \mathrm{kN}$. Even sections composed of concrete with 30 and $40 \mathrm{MPa} f_{c k}$ did not show significant reductions in their resistance. Evaluating the maximum flexural strength, a section with $f_{c k}=40 \mathrm{MPa}$ could to reach $86.80 \mathrm{kN} \cdot \mathrm{m}$, while the section with $f_{c k}=90 \mathrm{MPa}$ has a maximum flexural strength of $95.89 \mathrm{kN} \cdot \mathrm{m}$, indicating a $10.47 \%$ increase in flexural strength under a $125 \%$ increase in concrete characteristic compressive cylinder strength.

The visualization of the neutral axis equilibrium position at the flexural strength interaction diagrams limits allows to see the stress and strain states in each case. It appears in Figure 10 plot for $N=500 \mathrm{kN}$ that neutral axis intercepts the section in all interaction diagrams for all $\theta$ angles (NBR 6118 [5] domains 2, 3 and 4) at sections equilibrium limit 
states and that high strength concretes require smaller compressed areas. It is also interesting to point out that the concrete flexural strength contribution is higher with the increase of the $f_{c k}$. When $\theta=0^{\circ}$, the respective concrete and reinforcement contributions on flexural strength are $47 \%$ and $53 \%$ for $20 \mathrm{MPa}$ concrete sections and $65 \%$ and $35 \%$ for $90 \mathrm{MPa}$ concrete sections.

Table 1. Sections flexural strength $(\mathrm{kN} \cdot \mathrm{m})$.

\begin{tabular}{|c|c|c|c|c|c|c|c|c|c|c|c|c|c|c|c|c|c|c|}
\hline \multirow{3}{*}{$\begin{array}{c}\theta \\
\text { (rad) }\end{array}$} & \multicolumn{9}{|c|}{ Square } & \multicolumn{9}{|c|}{ Cross-format } \\
\hline & \multirow{2}{*}{$\begin{array}{c}\mathbf{N} \\
(\mathbf{k N})\end{array}$} & \multicolumn{8}{|c|}{$f_{\text {ck }}$ (MPa) } & \multirow{2}{*}{$\begin{array}{c}\mathbf{N} \\
(\mathbf{k N})\end{array}$} & \multicolumn{8}{|c|}{$\mathbf{f}_{\text {ck }}(\mathrm{MPa})$} \\
\hline & & 20 & 30 & 40 & 50 & 60 & 70 & 80 & 90 & & 20 & 30 & 40 & 50 & 60 & 70 & 80 & 90 \\
\hline \multirow{3}{*}{0} & 500 & 59.4 & 78.0 & 86.8 & 90.1 & 92.2 & 93.2 & 94.5 & 95.9 & 500 & 44.4 & 57.4 & 66.3 & 74.1 & 76.9 & 79.8 & 83.0 & 86.8 \\
\hline & 800 & 42.0 & 65.7 & 85.3 & 99.6 & 104.9 & 104.6 & 109.8 & 116.2 & 800 & 35.2 & 52.6 & 67.1 & 78.5 & 80.7 & 84.2 & 89.8 & 95.6 \\
\hline & 1200 & 9.1 & 41.3 & 67.5 & 88.9 & 97.7 & 103.9 & 111.2 & 119.6 & 1200 & 8.7 & 38.8 & 58.2 & 74.4 & 77.6 & 33.0 & 89.7 & 97.3 \\
\hline \multirow{3}{*}{$\pi / 4$} & 500 & 48.1 & 62.0 & 71.9 & 78.7 & 78.4 & 76.7 & 78.8 & 81.9 & 500 & 51.0 & 67.1 & 76.9 & 83.7 & 83.4 & 32.2 & 84.4 & 87.2 \\
\hline & 800 & 36.7 & 55.3 & 70.4 & 82.2 & 81.2 & 81.4 & 85.0 & 89.7 & 800 & 38.4 & 60.0 & 76.9 & 90.1 & 89.3 & 89.6 & 93.8 & 98.7 \\
\hline & 1200 & 9.1 & 38.4 & 59.4 & 76.1 & 78.0 & 81.1 & 85.6 & 92.6 & 1200 & 8.4 & 39.6 & 64.5 & 84.4 & 88.6 & 91.7 & 97.3 & 105.0 \\
\hline \multirow{3}{*}{$\pi / 2$} & 500 & 59.4 & 78.0 & 86.8 & 90.1 & 92.2 & 93.2 & 94.5 & 95.9 & 500 & 44.4 & 57.4 & 66.3 & 74.1 & 76.9 & 79.8 & 83.0 & 86.8 \\
\hline & 800 & 42.0 & 65.8 & 85.3 & 99.6 & 104.9 & 104.6 & 109.8 & 116.2 & 800 & 35.2 & 52.6 & 67.1 & 78.5 & 80.7 & 84.2 & 89.8 & 95.6 \\
\hline & 1200 & 9.3 & 41.5 & 67.8 & 88.9 & 977 & 103.9 & & .6 & 1200 & 8.8 & 38.8 & 58.2 & 74.4 & 77.6 & 3.0 & 89.7 & 97.3 \\
\hline \multirow{3}{*}{$\begin{array}{c}\theta \\
(\mathbf{r a d})\end{array}$} & \multicolumn{9}{|c|}{$\mathbf{T}$} & \multicolumn{9}{|c|}{$\mathbf{L}$} \\
\hline & \multirow{2}{*}{$\begin{array}{c}\mathbf{N} \\
(\mathbf{k N})\end{array}$} & \multicolumn{8}{|c|}{$f_{c k}(M P a)$} & & \multicolumn{8}{|c|}{$\mathrm{f}_{\mathrm{ck}}$ (MPa) } \\
\hline & & 20 & 30 & 40 & 50 & 60 & 70 & 80 & 90 & $(\mathbf{k N})$ & 20 & 30 & 40 & 50 & 60 & 70 & 80 & 90 \\
\hline \multirow{3}{*}{0} & 500 & 67.3 & 72.1 & 76.0 & 79.3 & 80.8 & 82.0 & 83.6 & 85.2 & 500 & 49.9 & 69.4 & 86.1 & 99.4 & 96.7 & 96.4 & 99.6 & 104.8 \\
\hline & 800 & 77.4 & 86.2 & 92.2 & 97.3 & 100.2 & & & 106.3 & 800 & 33.2 & 56.5 & 76.7 & & 95.6 & & 101.7 & 108.2 \\
\hline & 1000 & 57.9 & 91.5 & 100.4 & 106.9 & 111.2 & 13.8 & 116.6 & 118.6 & 1100 & 11.6 & 39.7 & 63.5 & 84.3 & 90.1 & 94.4 & 101.4 & 108.3 \\
\hline \multirow{3}{*}{$\pi / 4$} & 500 & 51.6 & 68.3 & 81.8 & 90.2 & 91.1 & 89.3 & 91.2 & 94.1 & 500 & 72.6 & 99.2 & 106.3 & 112.1 & 112.9 & 113.3 & 115.0 & 117.4 \\
\hline & 800 & 39.7 & 60.2 & 77.8 & 93.3 & 95.6 & 97.4 & & 109.4 & 800 & 47.0 & 82.4 & 114.1 & 132.1 & 135.7 & 136.2 & 138.3 & 143.1 \\
\hline & 1000 & 27.6 & 51.8 & 71.8 & 89.5 & 93.8 & 97.7 & 104.4 & 110.9 & 1100 & 16.0 & 56.3 & 92.4 & 125.1 & 137.9 & 144.0 & 153.9 & 159.9 \\
\hline \multirow{3}{*}{$\pi / 2$} & 500 & 48.1 & 62.1 & 70.9 & 78.5 & 79.5 & 80.6 & 83.2 & 86.3 & 500 & 67.6 & 74.3 & 78.6 & 81.9 & 82.5 & 82.9 & 84.1 & 85.7 \\
\hline & 800 & 37.3 & 55.8 & 71.4 & 83.1 & 86.2 & 87.2 & 91.9 & 97.3 & 800 & 55.7 & 78.7 & 90.1 & 96.9 & 98.3 & 98.0 & 100.1 & 104.0 \\
\hline & 1000 & 27.2 & 48.7 & 66.7 & 82.0 & 84.5 & 88.3 & 93.6 & 99.0 & 1100 & 29.8 & 63.2 & 87.0 & 103.7 & 102.8 & 103.5 & 109.0 & 113.0 \\
\hline \multirow{3}{*}{$3 \pi / 4$} & 500 & 57.3 & 72.9 & 82.2 & 89.5 & 87.6 & 87.0 & 89.1 & 92.1 & 500 & 53.4 & 66.6 & 76.1 & 83.2 & 79.2 & 77.7 & 80.3 & 83.6 \\
\hline & 800 & 36.4 & 66.1 & 85.1 & 96.4 & 96.2 & 96.2 & 99.5 & 104.0 & 800 & 42.2 & 60.2 & 74.0 & 85.3 & 81.9 & 81.2 & 84.5 & 89.4 \\
\hline & 1000 & 17.6 & 52.9 & 80.1 & 97.5 & 97.9 & 99.6 & 103.9 & 108.3 & 1100 & 21.5 & 48.2 & 67.0 & 82.1 & 80.8 & 81.6 & 86.6 & 91.6 \\
\hline & 500 & 46.2 & 68.2 & 88.3 & 106.4 & 112.9 & 119.4 & 127.1 & 135.6 & 500 & 67.6 & 74.3 & 78.6 & 81.9 & 82.5 & 82.9 & 84.1 & 85.7 \\
\hline$\pi$ & 800 & 27.1 & 54.0 & 76.7 & 97.5 & 107.4 & 115.1 & 124.8 & 135.4 & 800 & 55.7 & 78.7 & 90.1 & 96.9 & 98.3 & 98.0 & 100.1 & 104.0 \\
\hline & 1000 & 12.1 & 40.9 & 67.0 & 89.7 & 101.3 & 110.9 & 122.1 & & 1100 & 29.8 & 63.2 & 87.0 & 103.7 & 102.7 & 103.5 & 109.0 & 113.0 \\
\hline & 500 & 57.3 & 72.9 & 82.2 & 89.6 & 87.6 & 87.0 & 89.1 & 92.1 & 500 & 72.6 & 99.3 & 106.3 & 112.1 & 112.9 & 113.3 & 115.0 & 117.4 \\
\hline $5 \pi / 4$ & 800 & 36.4 & 65.9 & 85.1 & 96.4 & 96.2 & 96.2 & 99.5 & 104.0 & 800 & 47.0 & 82.4 & 114.1 & 132.1 & 135.7 & 136.2 & 138.3 & 143.1 \\
\hline & 1000 & 17.5 & 52.9 & 79.9 & 97.5 & 97.9 & 99.6 & 103.9 & 108.3 & 1100 & 16.0 & 56.3 & 92.4 & 125.1 & 137.9 & 144.0 & 153.9 & 159.9 \\
\hline & 500 & 48.1 & 62.1 & 70.9 & 78.5 & 79.5 & 80.6 & 83.2 & 86.3 & 500 & 50.0 & 69.4 & 86.1 & 99.4 & 96.7 & 96.4 & 99.6 & 104.8 \\
\hline $3 \pi / 2$ & 800 & 37.3 & 55.8 & 71.4 & 83.1 & 86.2 & 87.2 & 91.9 & 97.3 & 800 & 33.2 & 56.5 & 76.7 & 94.3 & 95.6 & 97.1 & 101.7 & 108.2 \\
\hline & 1000 & 27.2 & 48.7 & 66.7 & 82.0 & 84.5 & 88.3 & 93.6 & 99.0 & 1100 & 11.6 & 39.7 & 63.5 & 84.3 & 90.1 & 94.4 & 101.4 & 108.3 \\
\hline & 500 & 51.6 & 68.3 & 81.8 & 90.2 & 91.1 & 89.3 & 91.2 & 94.1 & 500 & 54.1 & 69.0 & 79.2 & 85.4 & 84.6 & 82.9 & 85.0 & 88.4 \\
\hline $7 \pi / 4$ & 800 & 39.7 & 60.2 & 77.8 & 93.3 & 95.6 & 97.4 & 103.0 & 109.4 & 800 & 38.7 & 60.3 & 76.7 & 89.0 & 85.4 & 85.1 & 89.1 & 93.9 \\
\hline & 1000 & 27.6 & 51.8 & 71.8 & 89.5 & 93.8 & 97.8 & 104.4 & 110.9 & 1100 & 14.9 & 45.1 & 66.6 & 84.1 & 82.3 & 83.3 & 88.6 & 94.3 \\
\hline
\end{tabular}

The relative proximity of the square sections interaction diagrams with different strength concretes in Figure 6 with $N=500 \mathrm{kN}$ can then be associated with the predominance of bending effects, where low concrete flexural strength 
contributions can be offset by the increase in the reinforcement steel contribution, since the applied axial force is relatively low.

On the other hand, the Figure 6 square sections interaction diagrams with $N=800 \mathrm{kN}$ now indicate some differences in relation to $N=500 \mathrm{kN}$ diagrams and greater distance between the interaction diagrams is perceived, being that the order of the flexural strengths agrees the ascending order of the $f_{c k}$. The only exception is the comparison of the interaction diagrams of the square sections with 50 and $60 \mathrm{MPa} f_{c k}$, which almost coincide outside the principal axis of inertia and move away only when are on them.

It is attested that for square sections with $N=800 \mathrm{kN}$, there is an increase in concrete flexural strength with $\theta=0^{\circ}$, which is $56 \%$ for a section with $f_{c k}=20 \mathrm{MPa}$ and increases up to $68 \%$ for those with $f_{c k}=90 \mathrm{MPa}$. In addition, Figure 10 plot for $N=800 \mathrm{kN}$ shows that neutral axis equilibrium positions continue to intercept the sections even if the compressed area predominates in the case of concretes with $f_{c k}$ from 20 to $70 \mathrm{MPa}$. The increase of concrete contribution on section flexural strength is, in this case, the main factor that interferes in the greatest distance between the Figure 6 square sections interaction diagrams with $N=800 \mathrm{kN}$.

The differences between the curves are greater in Figure 6 square section diagrams with $N=1200 \mathrm{kN}$, due to the increase of the compressed areas and, consequently, the concrete contribution on section flexural strength. However, when analyzing square sections equilibrium configuration when the angle $\alpha$ is zero in Figure 10 plot for $N=1200 \mathrm{kN}$, it is seen that only the square section with $f_{c k}=20 \mathrm{MPa}$ has neutral axis totally external to the section. All other sections with $f_{c k}$ values above $20 \mathrm{MPa}$ indicate partial compression, with the neutral axis intercepting the section, even with $N=1200 \mathrm{kN}$.

The same phenomenon is observed with the variation of the $N$ for sections with other shapes, showing that $f_{c k}$ the influence grows as the compressive axial force becomes predominant in relation to the bending moment.
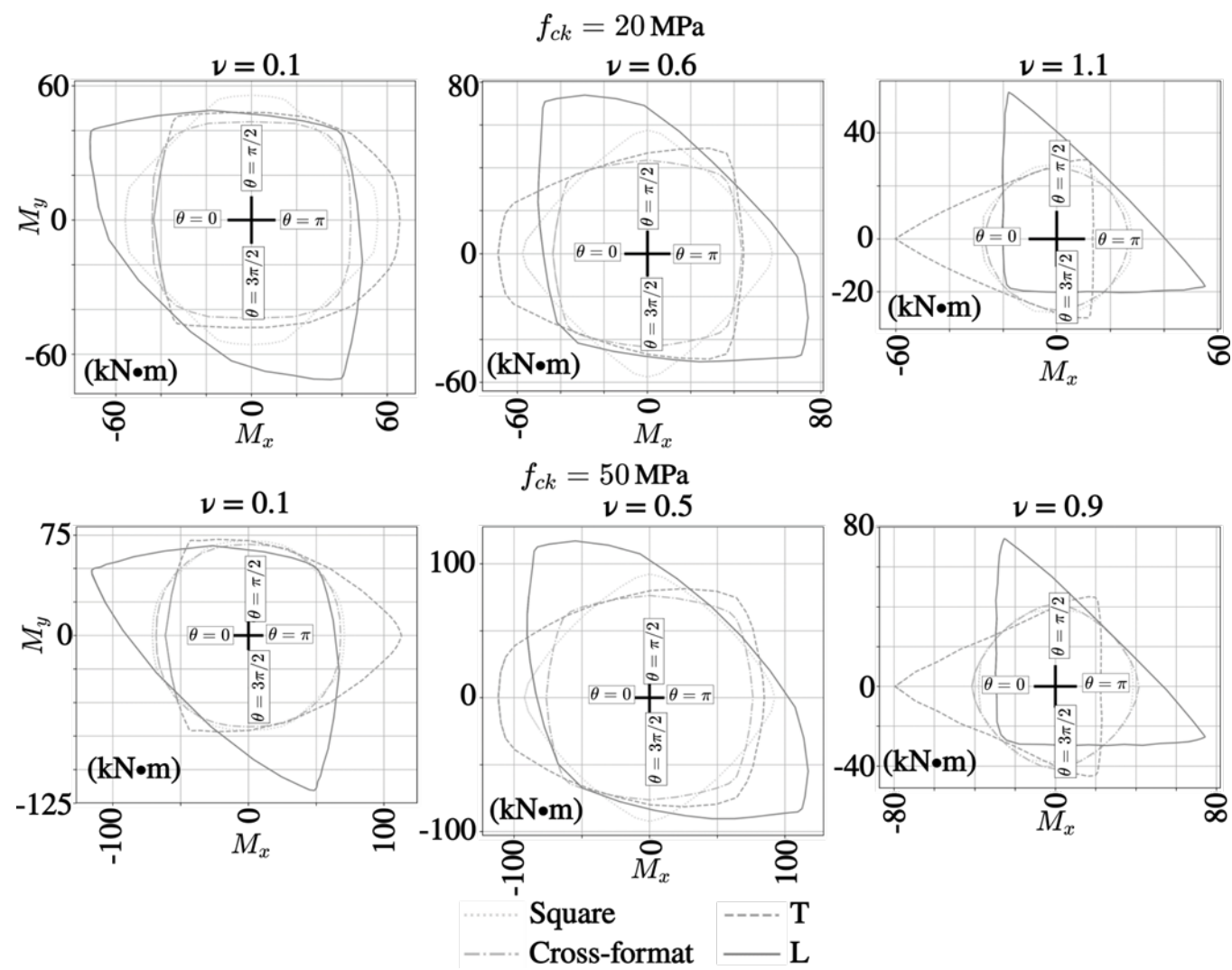

Figure 8. Influence of section shape on sections with $f_{c k}=20$ and $50 \mathrm{MPa}$. 
Another interesting perception in Figure 6 refers to the change in the interaction diagrams shape, described in point (b). It is observed that the $f_{c k} \leq 50 \mathrm{MPa}$ square sections interaction diagrams come out of a format next to a diamond $(N=500 \mathrm{kN})$ to a more rounded format $(N=800 \mathrm{kN})$. Meanwhile, curves of sections with 60 to $90 \mathrm{MPa} f_{c k}$ change inversely, having shapes with rounded corners under compression of $500 \mathrm{kN}$ and tending to diamonds when the axial force increases to $800 \mathrm{kN}$, with sharp corners in the principal axis of inertia. These tendencies become more explicit in Figure 6 diagrams in which the square sections are subjected to $N=1200 \mathrm{kN}$.
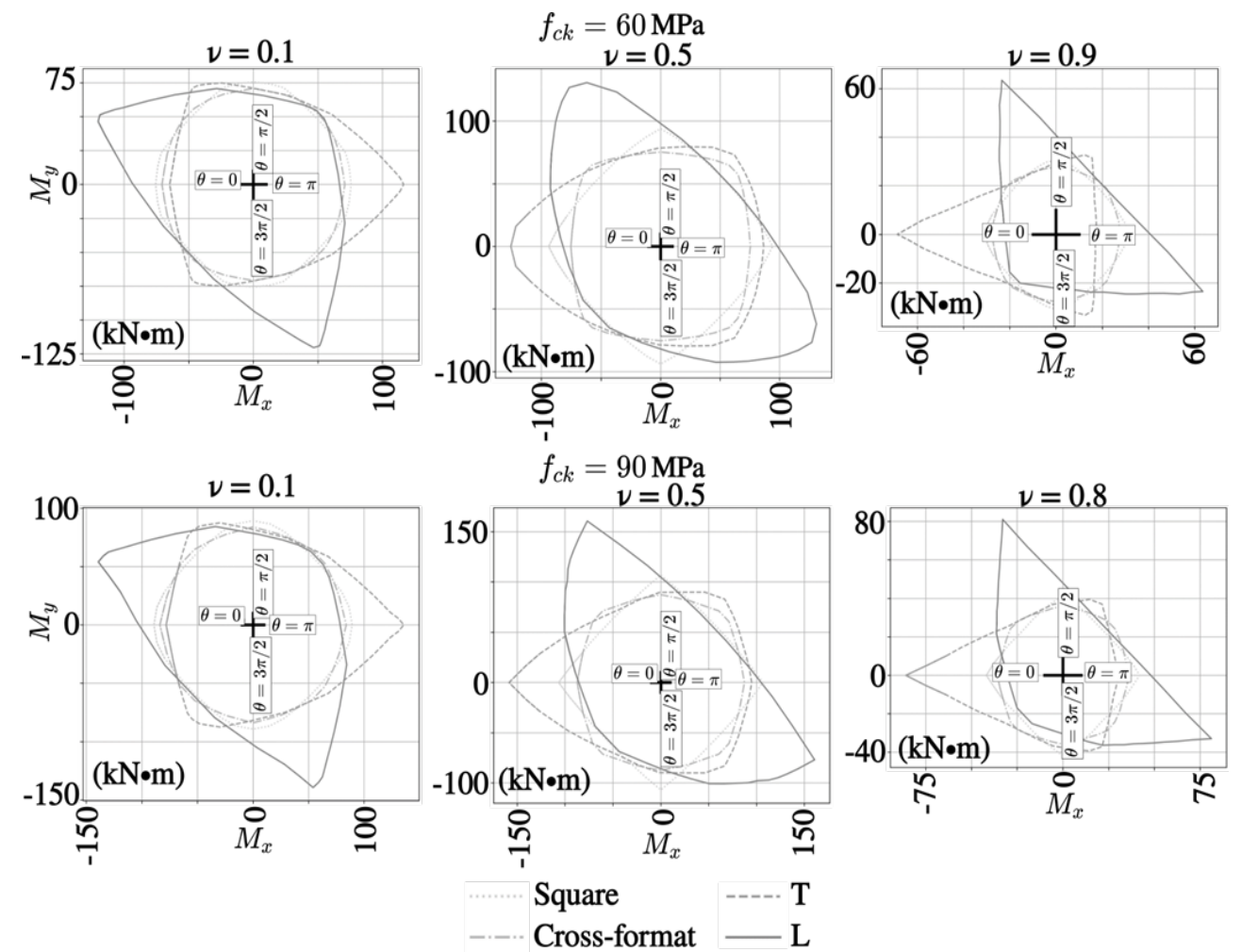

Figure 9. Influence of section shape on sections with $f_{c k}=60$ and $90 \mathrm{MPa}$.

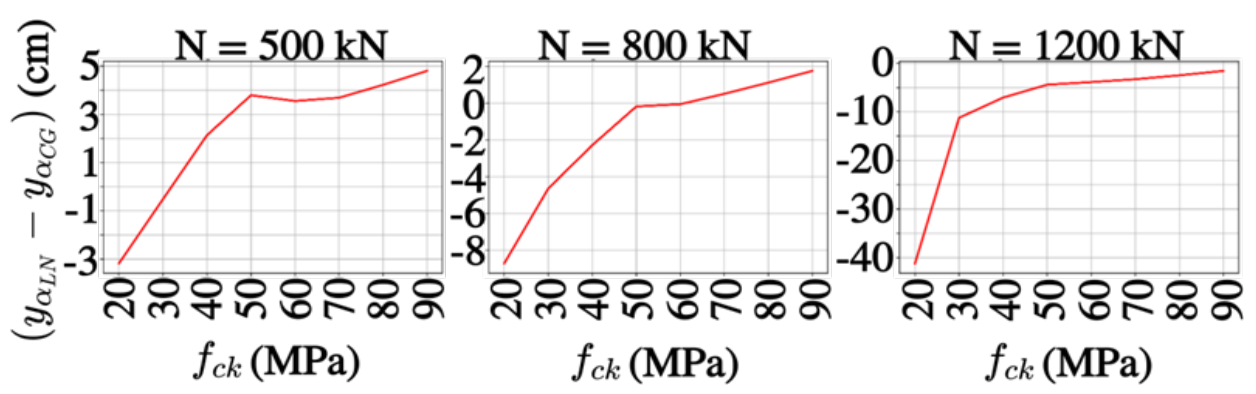

Figure 10. Relative position between neutral axis and centroid of square sections with $\alpha=0 \mathrm{rad}$.

In the case of square sections, the change of interaction diagram shapes is reversed when changing the formulation used to calculate the concrete compressive strength. As shown in Equations 2 to 5, the stress calculation parameters are different for concretes with $f_{c k}$ below and above $50 \mathrm{MPa}$, which is a limit that coincides with the different behaviors identified in the curves.

Interpreting Equations 2 to 5 it is seen that $\varepsilon_{c u}=0.35 \%$ for $f_{c k} \leq 50 \mathrm{MPa}$ concretes and this value decreases as $f_{c k}$ increases, until it reaches $0.26 \%$ to $f_{c k}=90 \mathrm{MPa}$. In parallel to this, $\varepsilon_{c 2}=0.2 \%$ to $f_{c k} \leq 50 \mathrm{MPa}$ and increases until it 
reaches $0.26 \%$ to $f_{c k}=90 \mathrm{MPa}$. This shows that, for high strength concretes $\left(f_{c k} \geq 50 \mathrm{MPa}\right)$, the plastic stretch (rectangle) of the stress-strain parabola-rectangle idealized diagram is smaller and smaller with the increase of $f_{c k}$ and does not exist when $f_{c k}=90 \mathrm{MPa}$.

In addition, the initial (more rigid) stretch of the Equation 2 stress-strain diagrams, which has parabolic shape in concrete of $f_{c k} \leq 50 \mathrm{MPa}$, is closing to a straight line when applied to concretes with greater strength, due to the decay of the $n$ coefficient value (equal to 1.4 for concretes of $90 \mathrm{MPa}$ ).

Observing the square section equilibrium configuration with $f_{c k}=20 \mathrm{MPa}$ under $N=500 \mathrm{kN}$, with an $\theta$ angle equal to $45^{\circ}$ (outside the principal axis of inertia), it is perceived that flexural strength is about $18 \%$ lower than that for $\theta=$ $0^{\circ}$. Although neutral axis stabilizes in similar positions in relation to the section centroid when $\theta=0^{\circ}$ and $\theta=45^{\circ}$ and the maximum concrete and reinforcement strains present close values, $\theta=0^{\circ}$ strength is higher due to the better reinforcement and compressed concrete areas distribution, making the concrete and the axial reinforcement strengths lever arm grater in relation to the centroid section.

The increase of $f_{c k}$ tends to reduce the relative differences of flexural strength between $\theta=0^{\circ}$ and $\theta=45^{\circ}$ to $N=500 \mathrm{kN}$, which softens the contours of the interaction diagrams. In the most extreme case, which is that of section with $f_{c k}=90 \mathrm{MPa}$, the concrete contribution on section flexural strength prevails, representing more than $65 \%$ of section flexural strength for $\theta=0^{\circ}$ and for $\theta=45^{\circ}$. As the plastic stretch does not exist for $f_{c k}=90 \mathrm{MPa}$ and the respective stress-strain curve is almost linear, the magnitude and the position of section axial strength change little and so the interaction diagrams become more rounded.

For high compression, as in Figure 6 plot for $N=1200 \mathrm{kN}$, square sections interaction diagrams shapes present change both for $f_{c k} \leq 50 \mathrm{MPa}$ and for $f_{c k}>50 \mathrm{MPa}$ concretes. The square section with $f_{c k}=20 \mathrm{MPa}$ is fully compressed to all angles and compressed concrete becomes responsible for most of the flexural strength section, being $61 \%$ and $55 \%$ when $\theta=0^{\circ}$ and $\theta=45^{\circ}$, respectively. The section flexural strength, in turn, have a close value for $\theta$ at both values, reflecting the almost round interaction diagram shape. In sections with $f_{c k} \leq 50 \mathrm{MPa}$, compressive strains tend to increasingly stay with values between $\varepsilon_{c 2}$ and $\varepsilon_{c u}$. This indicates that Equation 2 tends to promote uniform compressive strength $\sigma_{c}=0.85 f_{c d}$ throughout the section area. With this, $R_{c d}$ tends to the value $0.85 A_{c} f_{c d}$ in the various $\theta$ directions, i.e., tend to a constant value and the interaction diagrams look rounded.

In contrast, square sections with $f_{c k}>50 \mathrm{MPa}$ have strains between 0 and $\varepsilon_{c u}$ when subjected to high compression, in addition to the fact that neutral axis equilibrium position is closer to centroid. Thus, $\sigma_{c}$ also tends to vary in a way closer to the linear and $\theta$ angle variation significantly influences the value and lever arm of $N_{r d}$. Therefore, such concretes under $N=1200 \mathrm{kN}$ have interaction diagrams with straight lines and live corners in the principal axis of inertia.

Thus, a direct correlation between concrete constitutive relationship and the reinforced concrete sections behavior under combined bending and axial load is perceived. The sections internal equilibrium is sensitive to $\sigma_{c}$ distribution over concrete areas and $\varepsilon_{c u}$ values of which, in turn, interfere in the reinforcement deformation resulting in different interaction diagrams as the concrete constitutive relationship is modified.

Extending the analyses to the cross-format sections under low compression (Figure 6, $N=500 \mathrm{kN}$ ), $f_{c k} \leq 50 \mathrm{MPa}$ concretes provide interaction diagrams with format approaching a square with rounded corners, in which $\theta=(2 n+1)$ $\pi / 4$ directions, where $\mathrm{n}=0,1,2 \ldots$, present the maximum flexural strengths. At the same time, $f_{c k}>50 \mathrm{MPa}$ concretes lead to nearly round interaction diagrams shapes.

Shifting $N$ to $1200 \mathrm{kN}$, the shapes of $f_{c k} \leq 50 \mathrm{MPa}$ diagrams of cross-format sections become almost round, and this becomes sharper the smaller the $f_{c k}$. Meanwhile, the shapes of $f_{c k}>50 \mathrm{MPa}$ concretes become almost a smooth square. Comparing such observations with those made for square sections, it is perceived that the same factors guide the process, i.e., the concrete stress-strain relationship and the neutral axis position, associated with compressed areas and reinforcement distribution.

For " $\mathrm{T}$ " and " $\mathrm{L}$ " sections, the increase of $N$ also lead to a change in interaction diagrams shape and behaviors continue to be distinct for the two ranges of the Equations 2 to 5. However, both sections have only one axis of symmetry, unlike square and cross-format sections. This implies, among other things, greater reinforcement concentration in some regions (see Figure 3), something that should be taken into account in the analyses. In the case of "T" sections the reinforcement ratio is higher in the meeting of the flange with the web and, in the "L" sections, in the meeting between the two legs. 
Interaction diagrams shapes are nearly round for "T" with $f_{c k} \leq 50 \mathrm{MPa}$. For $f_{c k}=20 \mathrm{MPa}$, the maximum flexural strength happens when $M_{y}>0$ e $M_{x}<0$ (compressed section flange and most of the reinforcement). In this situation a reinforcement maximum tensile strength is the limiting factor for section flexural strength, since the section is inside the 3rd domain of Figure 1 and is the maximum utilization of compressed concrete and stretched reinforcement.

As $N$ increases to $800 \mathrm{kN}$ on Figure 6 and the neutral axis moves more and more in the direction of the "T" section most compressed point, the maximum flexural strength angle $\theta$ also changes. In this case, with $50 \mathrm{MPa} f_{c k}$, the "T" section still has interaction diagram with almost oval shape, but the maximum flexural strength is achieved when $M_{x}>0$ and $M_{y}=0$ (section web compressed and most of the reinforcement in traction). This is because the increasing of the $f_{c k}$ moves the neutral axis equilibrium position higher above the centroid section, something that decreases the concrete shortening strain but enhance reinforcement stretching, which becomes a strength limiting factor. The direction of greater flexural strength will then be the one that provides the greatest amount of stretched reinforcement $\left(M_{x}>0\right.$ and $\left.M_{y}=0\right)$.

When $f_{c k}$ exceeds $50 \mathrm{MPa}$, interaction diagrams are increasingly tapered in relation to the $M_{x}$ axis (positive direction) and the direction of greater flexural strength continues to be when $M_{x}>0$ and $M_{y}=0$, by the characteristic of stress equilibrium (concrete is compressed and most part of reinforcement is stretched). The bottleneck in question occurs due to the abrupt lowering of the concrete contribution on section flexural strength with small $\theta$ variations around the $\pi$ rad value, since the compressed areas vary abruptly, depending on the "T" section geometry.

Increasing compression and reaching up to $1000 \mathrm{kN}$ in Figure 6 " $\mathrm{T}$ " sections diagrams, there is a change of flexural strength interaction diagrams shapes of sections with $f_{c k} \leq 50 \mathrm{MPa}$, which begin to taper around the $M_{x}$ axis in its negative direction, presenting peak resistance to $M_{y}=0$. Such a configuration is one in which the maximum shortening strains are in the flange section, region with the highest reinforcement and concrete areas. A different situation is found for $f_{c k}>50 \mathrm{MPa}: M_{x}<0$ and $M_{x}>0$ flexural strengths are closer to each other in module. This means that concrete compressive capacity becomes as significant as reinforcement concentration in some regions, since a section is fully compressed.

In Figure 7 "L" sections diagrams under $N=500 \mathrm{kN}, f_{c k} \leq 50 \mathrm{MPa}$ concretes lead to interaction diagrams a little more rounded, tending to present sharp corners as $f_{c k}$ increases in the directions $\theta \approx 30^{\circ}$ and $\theta \approx 270^{\circ}$ to $20 \mathrm{MPa} f_{c k}$, $\theta \approx 40^{\circ}$ and $\theta \approx 230^{\circ}$ to $30 \mathrm{MPa} f_{c k}$ and $\theta \approx 50^{\circ}$ and $\theta \approx 220^{\circ}$ to 40 and $50 \mathrm{MPa} f_{c k}$. Such sharp corners correspond to flexural maximum strengths. Concretes with $f_{c k}>50 \mathrm{MPa}$ lead to round diagrams when there is a compression at region of section legs meeting and a straight diagram when the section legs free ends are compressed.

Under $N=1100 \mathrm{kN}$, "L" sections with $f_{c k} \leq 50 \mathrm{MPa}$ tend to generate interaction diagrams almost in the shape of a right triangle and this behavior is more pronounced the smaller the $f_{c k}$ is. Concretes with $f_{c k}>50 \mathrm{MPa}$, on the other hand, lead to interaction diagrams approaching an ellipse, whose largest dimension is almost parallel to "L" section symmetry axis.

To describe the phenomenon in point (c), we turn to the analysis of square sections. As an example, Figure 6 square sections diagrams with $N=500 \mathrm{kN}$ : it is noticed that for flexural strengths for angles $\theta$ close to $\pi / 4,3 \pi / 4,5 \pi / 4$ and $7 \pi / 4$, flexural strengths of concretes with $f_{c k}=50$ and $60 \mathrm{MPa}$ are greater than flexural strengths of concretes with $f_{c k}=70 \mathrm{MPa}$. This occurs similarly in all other sections when $N$ is relatively low.

This fact can be directly correlated to the initial part of the Equation 2 stress-strain curves, in which the curve of $f_{c k}$ $=50 \mathrm{MPa}$ is slightly stiffer than the curves of concretes with $f_{c k}=60$ and $70 \mathrm{MPa}$.

With the increase in compression in the sections, concretes with $f_{c k}=60$ and $70 \mathrm{MPa}$ provide greater flexural strength than the concretes with $f_{c k}=50 \mathrm{MPa}$. However, in some $\theta$ directions of the " $\mathrm{T}$ " and "L" sections, it is still possible to verify the phenomenon of point (c) for $N$ higher values. In this case, the $\varepsilon_{c u}$ strain (greater for concretes with $f_{c k}=50 \mathrm{MPa}$, compared to its corresponding to $f_{c k}=60$ and $70 \mathrm{MPa}$ ) may be associated with the fact.

\subsection{Shape influence on section flexural strength}

The comparisons are performed with the section flexural strength interaction diagrams of the four section shapes, grouped in the same graph. The sections are subjected to the same dimensionless axial force $v$ have concretes with same $f_{c k}$ and same concrete and reinforcement areas. 
Regardless evaluated $f_{c k}$, it is perceived, by the interpretation of Figure 8 and Figure 9 plots where $v=0.1$, that the rebars positioning is predominant. The more reinforcement area close to the most stretched point in the section, the greater the section flexural strength. This is because, under low dimensionless axial forces, the neutral axis tends to intercept the section and when there is a higher amount of tensile resistant material in the stretched areas, grater is the section flexural strength.

Looking at the $M_{x}$ value when $M_{y}=0$, the highest negative values of the interaction diagrams are "L" sections, since the rebars distribution allows a greater reinforcement concentration in the stretched region. On the other hand, when $M_{x}>0$ and $M_{y}=0$, the " $T$ " section flexural strength prevails, because it presents much of the rebars in the flange (stretched). "L" sections also have the highest flexural strength when $M_{x}=0$ and $M_{y}<0$, confirming the influence of rebars distribution, concentrated in the meeting of section legs. The square section, in turn, deserves attention when $M_{x}$ $=0$ and $M_{y}>0$ since, in this case, it has the largest reinforcement area close to the section maximum tensile strain point.

Also on Figure 8 and Figure $9 v=0.1$ plots, it is attested that the cross-format sections interaction diagrams have the smallest coverage area. This fact is due to much of the reinforcement area is concentrating remarkably close to the centroid section, leading to the low utilization of rebars (small lever arm of reinforcement axial strength) and the maximum section allowed curvature. As $f_{c k}$ increases, however, cross-format sections interaction diagrams become closer to one of square sections. This is likely to occur by changing the position of the neutral axis with the variation of the $f_{c k}$, since concretes with higher $f_{c k}$ tend to require less compressed area. Thus, in the case of cross-format section, more and more rebars tend to get stretched and thus increases the flexural strength.

Under intermediate dimensionless axial forces of Figure 8 and Figure 9, the comparison between the sections changes considerably and the reinforcement distribution remains the predominant factor on flexural strength. However, the influence of rebars occurs differently since the reinforcement concentration in the most compressed regions provides the higher flexural strengths. Contrary to what is perceived for $v=0.1$, the $N$ increase causes the "L" sections interaction diagrams to predominate over the others when $M_{x}>0$ and/or $M_{y}>0$, that is, when the highest compressive strains occur at the meeting of the section legs where most of the reinforcement steel is. With $M_{y}=0$ and $M_{x}<0$, there is the predominance of " $T$ " section interaction diagrams, because the largest compressive strains and most of the reinforcement is in the flange section. When $M_{x}=0$ and $M_{y}<0$, it is perceived that the square section is the one with the highest flexural strength, because $50 \%$ of total reinforcement is shortened according to $\varepsilon_{c}$ close to $\varepsilon_{c u}$, something that does not occur with the other sections.

However, when $v$ increases further and assumes values around 1.0, characterizing high compression rates, it is demonstrated by Figure 8 and Figure 9 that $f_{c k}$ becomes relevant as reinforcement geometry. When observing the sections whose shape provides concrete and reinforcement areas close to the section point with the maximum compressive strain, they are the same sections that stand out for the highest flexural strength. Thus, the comparison of mechanical behavior of the sections from the point of view of combined bending and compression, it is attested that the concrete and reinforcement geometry optimization will depend on the values of the applied force and the mechanical properties of these materials.

\section{CONCLUSIONS}

This work developed a computational algorithm capable of calculating the moment-axial force-curvature relationship of arbitrary shape polygonal reinforced concrete sections, which uses the NBR 6118 [5] parabola-rectangle diagram as the concrete constitutive relationship. From the elaboration of the calculation routines and the evaluation of the results obtained, it is possible to conclude that:

a) the nonlinearity of the calculation process of reinforced concrete sections flexural strengths requires iterative balance calculation, given the number of variables interfering with the problem. Therefore, more efficient convergence methods tend to accelerate the speed at which the problem is solved;

b) under low applied axial forces, the $f_{c k}$ increase has a lower influence, when compared to the interference of this factor in the interaction diagrams for higher applied axial forces;

c) the increase of applied axial force tends to change not only the section flexural strength magnitude but also alters the interaction diagrams shape. The changes, however, tend to be different for concretes below and above $50 \mathrm{MPa}$. It is worth to evaluate whether the behavior change proposed by the Brazilian standard for concrete stress-strain diagrams for $f_{c k}>50 \mathrm{MPa}$ satisfactorily represents the mechanical behavior of structural elements. There is, in the 
vicinity of $f_{c k}=50 \mathrm{MPa}$, a relevant discontinuity in the function governing limit strains $\varepsilon_{c 2}$ and $\varepsilon_{c u}$ and the impact of this on the sections calculation is considerable, as shown in the interaction diagrams;

d) in the initial sections of Equation 2 stress-strain diagrams, concretes with $f_{c k}=50 \mathrm{MPa}$ are more rigid than the concretes of $f_{c k}=60$ and $70 \mathrm{MPa}$, making the flexural strength interaction diagrams of concretes with lower $f_{c k}(50$ $\mathrm{MPa}$ ) more comprehensive than those of concrete with higher $f_{c k}(60$ and $70 \mathrm{MPa})$, especially when the axial force $N$ is smaller;

e) as for the evaluation of the performance of sections with different shapes for all $v$ values, the rebars distribution is among the most important factors. If $v$ is low, the reinforcement concentration next to the section most stretched point is what provides the highest flexural strengths. When $v$ increases, the reinforcement concentration in the vicinity of the section most shortened point leads the sections to higher flexural strengths. In the case where $v$ is close to 1.0, the concrete compressive strength assumes a main role and the presence of compressed areas close to the section point with the higher compressive strain interferes with flexural strength sections.

\section{REFERENCES}

[1] L. Pallarés, P. F. Miguel, and M. A. Fernández-Prada, "A numerial method to design reinforced concrete sections sujected to axial forces and biaxial bending," Eng. Struct., vol. 31, no. 12, pp. 3065-3071, Dec 2009, http://dx.doi.org/10.1016/j.engstruct.2009.08.006.

[2] A. Dall'Asta and L. Dezi, "Design of RC sections with generic shape under biaxial bending," J. Struct. Eng., vol. 118, no. 4, pp. 1138-1143, Apr 1992, http://dx.doi.org/10.1061/(ASCE)0733-9445(1992)118:4(1138).

[3] A. Fafitis, "Interaction surfaces of reinforced-concrete sections in biaxial bending," J. Struct. Eng., vol. 127, no. 7, pp. 840-846, Jul 2001, http://dx.doi.org/10.1061/(ASCE)0733-9445(2001)127:7(840).

[4] R. Vaz Rodrigues, "A new technique for ultimate limit state design of arbitrary shape RC sections under biaxial bending," Eng. Struct., vol. 104, no. 1, pp. 1-17, Dec 2015., http://dx.doi.org/10.1016/j.engstruct.2015.09.016.

[5] Associação Brasileira de Normas Técnicas, Projeto de Estruturas de Concreto - Procedimento, NBR 6118, 2014.

[6] F. A. Torrico, "Analise teórica e experimental do comportamento de pilares esbeltos de concreto de alta resistência, considerando a ductilidade,” Ph.D. dissertation, Esc. Eng. São Carlos. Univ. São Paulo, São Carlos, 2010.

[7] G. Campione, L. Cavaleri, F. Di Trapani, G. Macaluso, and G. Scaduto, "Biaxial deformation and ductility domains for engineered rectangular RC cross-sections: A parametric study highlighting the positive roles of axial load, geometry and materials," Eng. Struct., vol. 107, no. 15, pp. 116-134, Jan 2016, http://dx.doi.org/10.1016/j.engstruct.2015.10.030.

[8] L. P. Souza, "Instabilidade e dimensionamento de pilares de concreto armado de seção poligonal submetidos à flexão composta oblíqua,” M.S. thesis, Prog. Pós-grad. Eng. Constr. Civ., Univ. Fed. Paraná, Curitiba, 2017. [Online]. Available: https://hdl.handle.net/1884/59886

[9] S. Gillies. "Shapely 1.6.2.postl”. GitHub, 2017. Available: https://github.com/Toblerity/Shapely (accessed June 14, 2017).

[10] A. Klöckner. "Meshpy 2016.1.2”. Python Software Foundation, 2016. Available: https://pypi.python.org/pypi/MeshPy (accessed Aug 3, 2017).

Author contributions: LPS: algorithm computational implementation, data analysis, writing; MAA: supervision, revision, translation.

Editors: Mauro de Vasconcellos Real, José Luiz Antunes de Oliveira e Sousa, Guilherme Aris Parsekian. 